\title{
Research on Organization Optimization of Urban Public Traffic Line Network in Tianjin*
}

\author{
Jun Li \\ Tianjin Vocational Institute \\ Tianjin, China
}

\begin{abstract}
The organization optimization of bus network is the basis of the collaborative work of all aspects of public transportation system. It runs through the optimization of the whole bus system and plays a vital role in the optimization of bus system operation management. Based on the analysis of the status quo and existing problems of the development of Tianjin public transport network, this paper analyzes the strategy of Tianjin public transport network organization optimization based on the development law of public transport network, and finally proposes targeted countermeasures for existing problems, hoping to provide a certain guiding role for the actual work.
\end{abstract}

Keywords-public transportation system; transportation network organization optimization; rail network

\section{INTRODUCTION}

With the development of the city's economy, the number of urban motor vehicles has greatly increased, and urban traffic problems have become increasingly prominent, which has become the focus of people's attention. In order to solve the problems of traffic jam, environmental pollution and energy shortage caused by urban traffic, vigorously developing public transportation is one of the most direct and effective ways to optimize the allocation of transportation resources and ensure the sustainable development of urban transportation

Tianjin is one of the four municipalities directly under the Central Government, a first-tier city, a livable city, and an important port city in the north. Its city scale is expanding year by year, and its public transportation optimization must be adjusted in time to cope with the smooth development of the city. Among them, the optimization of the network organization of public transportation runs through the beginning and end of the operation and management of urban bus network, and plays a vital role in the continuous optimization of the bus system.

\section{THE CONNOTATION AND SignifiCANCE OF URBAN PUBLIC TRANSPORTATION NETWORK ORGANIZATION OPTIMIZATION}

The urban public transportation network refers to a

*Fund: Tianjin Philosophy and Social Science Planning Project "Research on the Improvement of Tianjin Port Service Function Based on Service Supply Chain". Project number: TJYYWT15-019 network composed of public transportation lines. It consists of a station and routes between stations. Once it is determined, it is relatively stable over a long period of time. It belongs to the static facilities in the public transportation system and is the basis of other public transport planning.

If the static network layout is unreasonable, then both the system scheduling and technical application will face the ceiling of optimization, unable to play the optimal effect under the existing scheduling and application capacity. First of all, the excellent public transportation network design can realize the reasonable guidance of passenger flow, so that the citizens can conveniently and quickly take the public transportation system to achieve the purpose of travel, and at the same time, the reasonable distribution of traffic in the urban line network and a relatively uniform density can be realized. In addition, a reasonable network, especially the site layout, also concerns the operating income of public transportation companies. Only when the profits of public transport enterprises are maintained at a certain level, can the public transport enterprises develop healthily and continuously, and then the public transport system can operate healthily and for a long time, and technology upgrading or facility updating can be realized when conditions permit as well. In addition, with the continuous increase in the number of private cars, reasonable and effective bus stop site settings can also alleviate the increasingly serious traffic conditions in modern society to a certain extent.

\section{ThE STATUS QUO AND PROBLEMS OF THE}

\section{DEVELOPMENT OF PUBLIC TRANSPORTATION IN TIANJIN}

\section{A. Development Status of Tianjin Bus Network}

As of 2018, there were 791 bus operation lines in Tianjin, with a line length of 15,327 kilometers, an increase of $24.4 \%$ over the "Twelfth Five-Year Plan", and zero-distance transfer with all 84 subway stations; there are more than 2,000 bus stations in various areas of the central city, and the bus station has achieved full coverage of 500 meters. With more than 100 bus stations, it has formed a comprehensive bus network system combining "point-line-surface". [12]

\section{B. Development Status of Tianjin Rail Transit Network}

As of 2018, Tianjin metros have 5 lines and 89 stations, with a total length of about 150 kilometers. According to the 
city's overall planning and comprehensive transportation planning, the Tianjin Urban Rail Transit Long-Term Annual
Network consists of 28 lines with a total length of 1,380 kilometers, [13] as shown in "Fig.1".

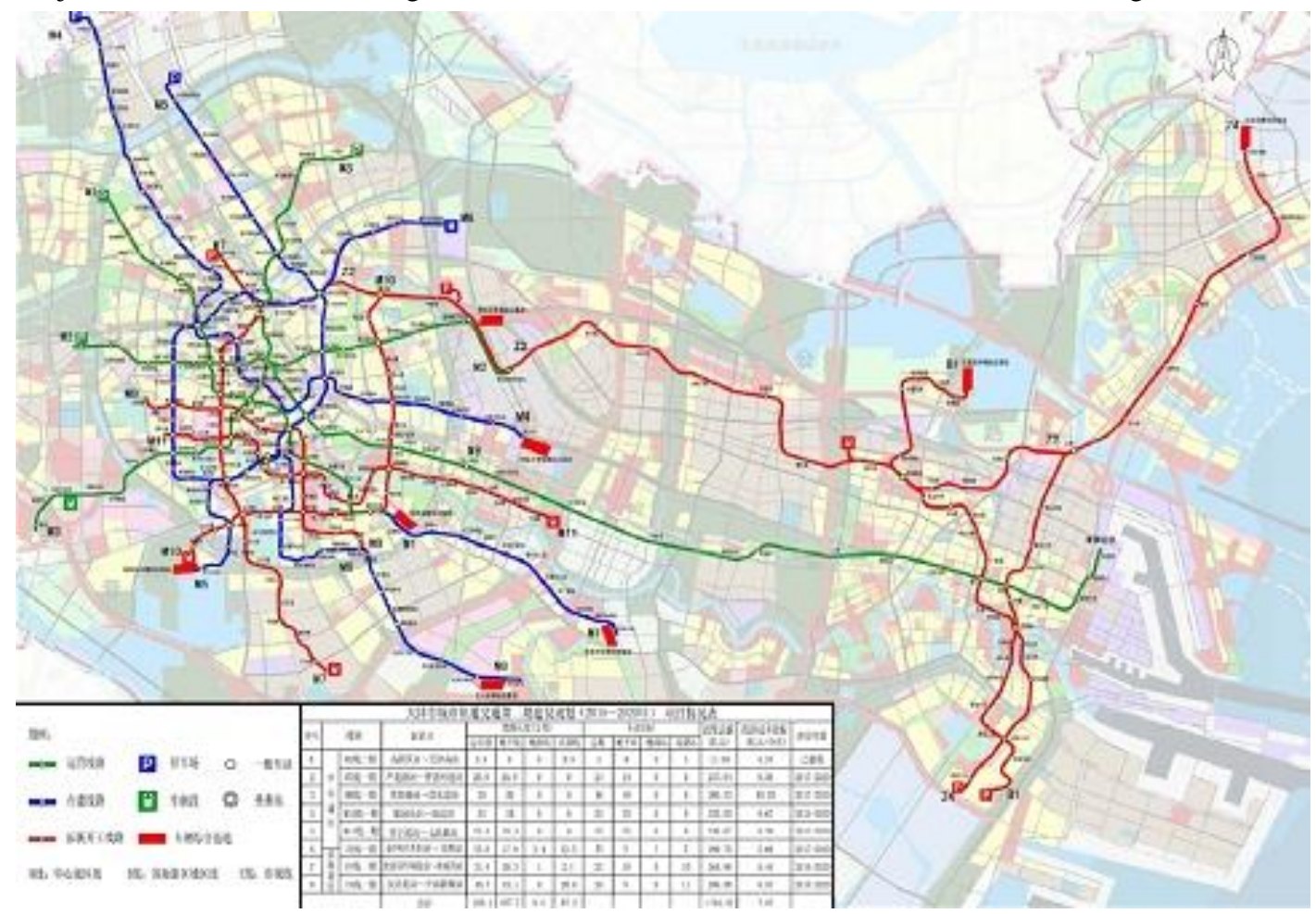

Fig. 1. Schematic Diagram of the Second Phase of Tianjin Urban Rail Transit Construction Plan (2015-2020).

\section{Problems and Shortcomings in Tianjin Public Transportation Network System}

In general, the Tianjin public transportation network system has begun to take shape, the site hardware and software equipment is getting better and better, and the service level is also constantly improving, which plays a pivotal role in the daily public transportation of the citizens and plays its function of public service well.

However, the existing bus network system also has many problems and deficiencies, which can't meet the needs of the citizens, and as a result, the bus sharing rate is low. These problems are mainly reflected in the following aspects:

1) The uneven distribution of bus lines leads to traffic jam: At present, the bus lines of the main roads in Tianjin are over-concentrated, and the bus lines at some stations are too dense. For example, Haiguangsi Station and the Department Store Station have 35 bus lines passing through these two stations respectively. In the peak period, the throughput of bus vehicles that needs to be handled in bus stations is overmuch. A large number of buses stopping at the bus station will form a major obstacle to traffic and affect the traffic capacity of the road.

2) Uneven heating and cooling of the line, insufficient adaptability of capacity and demand: Passengers of some existing bus lines are quite a lot in Tianjin, and it is over crowded in rush hours in the bus. However, there are also bus lines that are often in an empty state. For example, many large-scale residential areas on the road of No. 327 bus are densely populated residential areas, with a permanent population of more than 30,000 people, and the travel demand is very large. In addition, the route is connected to the Jinggangshan Road Bus Station and Jingiiang Road and Metro Line 2 and the connection between the Weiguo Daoqi and Xinyuan Bus Stations and the Central Link is convenient for the public to change to the subway or to the Central Line to change to the trunk bus road. Therefore, it is very popular among the public and transports more than 2,100 passengers per day. The No. 329 bus line, which passes through many traditional downtown areas, such as office buildings, business centers and shopping centers, has a large passenger flow. However, due to the low density of surrounding residents, bus network is very dense, and the demand of citizens is not strong, there are only more than 40 passengers per day.

3) The distribution of the line network is still missing: On the one hand, after years of continuous construction, the Tianjin bus network has initially reached full coverage of the urban area. However, in some directions and areas, there are still blank spots covering the bus network. Some citizens, especially those living in newly developed communities (such as the newly-developed buildings in Meijiang area), feel it inconvenient about public transportation.

On the other hand, the development of Tianjin's public rail transit is obviously lagging behind, which is reflected in the lack of track lines and sparse sites relative to the scale of 
urban development, resulting in low coverage of rail transit network and lack of accessibility, and as a result, the share rate of rail transit for public transportation is too low. In fact, Tianjin is the second city in China with subways. The first line was officially opened to traffic on December 28, 1984 and it has a longer history than other first-tier cities. However, the development of the Tianjin metro entered a stagnation phase and the construction of the second railway line, Jinbin light rail line 9, didn't begin until 2001. In the next 10 years, the Tianjin Metro has been steadily developing, but it still can't meet the growing travel needs of the citizens.

4) Lack of public transportation development in noncentral urban areas: At present, Tianjin has actively carried out urban and rural public transport integration to achieve the equalization of urban and rural public transport services in the new four districts, but the results have not yet been prominent. Doing a good job in urban and rural bus integration is not only a need to meet the needs of citizens' travel, but also an effective means to promote local exchanges and promote the integration of Beijing, Tianjin and Hebei.

\section{TIANJIN PUBLIC TRANSPORTATION NETWORK OPTIMIZATION PRIORITY STRATEGY ANALYSIS}

For different public transportation modes, the way and focus of optimization of the network system is not the same.

The city bus line network is relatively flexible, the adjustable space is large and the adjustment operation is easy to implement; the laying of urban rail transit network is accompanied by the systematic engineering construction work such as tunnel excavation, multi-layer station construction and track laying, which has the characteristics of large investment, long construction period and great construction difficulty and once the line is determined through construction, it is not easy to change without special circumstances. Therefore, in the planning of the urban rail transit network, it is especially necessary to pay attention to the planning, investigation and research work in the early stage, so that the laying of the track network is in line with the needs of the long-term development of the city.

Based on the basic situation of Tianjin, Tianjin urban rail transit has experienced a period of stagnation in development, and the development in the later period is relatively slow and currently, a perfect and scaled network system has not been formed. At present, the construction is the most basic and necessary backbone of the orbital network with the foundation and necessity of construction, and the space that can be considered is small. And for a long time, buses are still the main force of public transportation, taking on most of the passenger flow.

Therefore, on the one hand, in the short-term, when energy and financial resources are limited, priority should be given to optimizing the Tianjin public transportation network; on the other hand, in order to adapt to the long-term healthy development of urban public transportation, it is necessary to accelerate the construction of urban rail transit network and at the same time, pay attention to the overall planning of the city, and make scientific design and layout of the network in advance.

\section{TIANJIN Bus NETWORK ORGANIZATION OPTIMIZATION SUGGESTION}

In view of the main problems in the Tianjin public transportation network, and drawing on the excellent case experience of other countries or cities, this paper proposes the following suggestions for improvement.

\section{A. Focusing on Speeding up the Construction of Rail Transit Network Encryption and Rational Long-term Planning}

Compared with other public transportation modes, urban rail transit has the advantages of large volume, high speed and high reliability. In theory, it is a public transportation mode that citizens prefer. However, due to the imperfect development of the Tianjin subway, the subway station is sparse, and the metro line coverage area is small, resulting in a low share of the public rail transit travel in Tianjin, less than $14 \%$ in the public transportation system. In addition, vigorous development of urban rail transit can save municipal land resources, reduce noise pollution, reduce interference to existing transportation networks, save energy and reduce air pollution. Therefore, the construction of urban rail transit in the construction of urban public transport system is an inevitable trend to promote urban transport development, improve the quality of urban construction, and improve the satisfaction of citizens' lives.

\section{B. Encrypting Public Transportation on Crowded Roads}

There are some road sections in Tianjin, such as Chongrenli-Chongqing Road Section, Xiushan GardenChangzhou Road Section, Youyi Road-Children's Hospital Section, etc., which exist some prominent congestion problems.

For the management of congested road sections, relevant units and departments shall organize the quantification and grading of the congestion of each road section, and divide the service level according to the actual traffic volume of the road and the ratio of the bearable traffic $(\mathrm{V} / \mathrm{C})$, and make targeted bus service preference according to the roads of different grades. For the congested roads with large passenger traffic and large traffic demand, the bus routes should be intensified according to the level of road service level, and urban rail transit should be designed and planned. And it is also necessary to encourage citizens to shift from private transportation to public transportation in a hierarchical and focused way.

However, only by means of a single way of intensifying the network, instead of easing the congestion problem, it will lead to further congestion caused by the increase of bus traffic and the frequent getting on and off of passengers on the platform. In order to match the bus convenience facilities with increased density of road sections, the private car limit policy should be implemented in the peak section of the road, and the convenience of the bus line should be used to replace 
the private car travel demand, and the combination of dredging and congestion can effectively control the jam of key road sections.

In addition, the planned construction of the urban underground rail public transport in the core congestion section of the central city will gradually improve the traffic congestion and truly improve the urban traffic conditions.

\section{Implementing Weak Area Site Encryption}

On the one hand, due to the dense flow of people in the downtown area of Tianjin, especially the large public facilities (such as the major top three hospitals, primary and secondary schools, large supermarkets), the parking space is in short supply; passengers get on and off frequently, and traffic congestion frequently occurs. The addition of subway stations or bus combination sites around the city's top three hospitals, primary and secondary schools, and large supermarkets will facilitate the public's travel to these infrastructures, making the public nature of public facilities more visible; on the other hand, it can encourage the public to use the mode of public transportation to achieve daily travel, so as to alleviate the shortage of parking space in vehicles; in addition, the combined stations can disperse bus stop locations and prevent further traffic congestion caused by bus concentration and queues.

On the other hand, although the accessibility of the subway in the downtown area of Tianjin has yet to be improved, the bus stations have been relatively densely distributed, and the bus stations can be reached by walking 500 meters basically. In recent years, Tianjin has actively explored some of the emerging urban areas, such as a number of new buildings and residential areas in the Meijiang area, and the Haihe Education Park in Jinnan District. While actively exploring new urban areas, it is necessary to build supporting public transportation facilities, focus on intensifying public transportation stations, and focus on planning the construction of future subway stations to facilitate the travel of citizens in the area.

\section{Adding Short-distance Buses in the Existing Bus Blind Areas}

There are some "blind areas" for bus network services in Tianjin. Especially, the subway stations are relatively sparse. How to solve the "last kilometer" problem from the doorstep to the public transportation site is one of the important issues to improve the quality of citizens' travel. However, under the current situation that urban bus lines are relatively dense, it is not the most ideal way to open more complete bus routes through these communities. In addition, many streets in the community are relatively narrow, and there are practical obstacles to the passage of large-scale buses, which is not conducive to daily traffic safety for residents. Therefore, a number of short-distance bus lines should be opened for these communities, and small-vehicle transportation and reduced-charge mode operations should be carried out to transport passengers to larger nearby hubs where there is a greater concentration of bus lines. So that residents living in the hinterland of the community can enjoy the bus service of "home entrance", shorten the walking time required for public transportation, increase the attraction of public transportation to the public, improve the quality of service, and eliminate the blind spot of public transportation.

\section{E. Strengthening the Matching of Bus Lines and Demands}

In view of the current problems of uneven heating and cooling of the line, as well as insufficient adaptability of capacity and demand in Tianjin, the relevant departments should organize the inventory and screening of the over-cold and over-heated lines to identify the lines to be controlled. For the over-heated lines, the main passenger-intensive stations on the line should be screened, and the express line should be opened according to the main departure place and destination of the passengers to realize the distribution of the passenger flow and the distribution pressure on the online network; meanwhile, the frequency of over-heated lines should be increased, and the carrier vehicles should be replaced with double-decker buses and other vehicles with larger carrying capacity, so as to realize efficient transportation of passengers. For the over-cold lines, by merging multiple cold lines and other bus lines to annex the cold-line travel passenger demand, canceling the operation of the separate sub-cooled line, changing or extending the cold lines, so that the line caters to the travel needs of more citizens. Optimizing the over-cold lines to make full use of existing resources and reduce waste of resources.

\section{F. Making Great Efforts to Build BRT}

Based on the current situation that the public rail transit in Tianjin is still underdeveloped, the bus line should continue to optimize the conventional operating line network, and should also vigorously develop the rapid transit system to form a multi-level and multi-functional urban public transportation integrated transportation network.

The construction of the BRT system should aim at accelerating the speed of bus transportation in the morning and evening peaks on the basis of the conventional bus line network, and abolish the inefficient route and avoid the means of bypassing the road to shorten the distance between the key stations, in addition, by taking more fast roads, avoiding traffic lights as much as possible, and maximizing the use of bus lanes, the speed of public transportation is greatly improved.

The construction of bus rapid transit line will greatly facilitate the long-distance commuting of office workers and students, shorten their commuting time, improve the quality of life of citizens and enhance their trust and satisfaction in urban public transportation while reducing the travel time cost of citizens.

\section{G. Developing "Hub-and-spoke" Bus Network System and Paying Attention to Line Network Layering}

"Hub-and-spoke" network transportation can transfer and transship using a unified relay hub in the system, and then send it to a high-speed relative direct path for efficient transit. 
To build a "hub-and-spoke" bus line network in Tianjin, it is necessary to build a multi-level transportation hub based on the existing network of the city and the distribution of residents, especially the comprehensive transportation hub combining rail transit and bus, and build multi-level, efficient bus network on this basis. It is necessary to connect high-capacity and high-speed public transportation hubs to fast, large-capacity public rail transit, use conventional, lowgrade bus lines to connect low-level public transportation hubs and passenger flow dense points to form a clear hierarchy, rapid passenger flow and door-to-door efficient public transport system, which can achieve economies of scale and reduce transportation costs while achieving relatively fast transportation and relatively clear and convenient management.

\section{CONCLUSION}

Further accelerating the construction and improvement of the modern public transportation system that meets the needs of social and economic development and in line with the conditions for the construction of human settlements is of great significance to Tianjin, which is in the critical period of its modernization process, and also helps Tianjin gradually build into an international port city with prosperous economy, social civilization, developed science and education, perfect facilities and beautiful environment, as well as an economic center and ecological city in the north. It is believed that with the joint efforts of many parties in the society, Tianjin can establish a public transportation network system that is more complete, efficient and matches the needs of the citizens, and promotes the social construction of Tianjin to a new level.

\section{REFERENCES}

[1] Zhai Hezhou, Yang Jingshuai. Thinking on the Classification Planning of Chengdu City Bus Line Network [J]. Journal of Transportation Engineering and Information, 2006, 01: 64-72. (in Chinese)

[2] Hu Qizhou, Shi Qin, Zhang Weihua, Zhang Aiping. Ideal Decision Method for Urban Bus Line Network Optimization [J]. Journal of Traffic and Transportation Engineering, 2005, 01: 82-85. (in Chinese)

[3] Hu Qizhou, Lu Huapu, Dai Shuai, Zhang Xiaoli. Matter Element Analysis Model for Urban Bus Line Network Rating [J]. Journal of Highway and Transportation Research and Development, 2010, 03: 114-118+124. (in Chinese)

[4] Wang Zhenbao, Chen Yanyan. Integrated Planning Method of Public Transportation Network in Big Cities [J]. Planner, 2011, S1:137-140. (in Chinese)

[5] Li Zhi, Zhou Shenglu, Wu Shaohua, Dai Yuying, Chen Long, Lu Ligang. The Impact of Nanjing Metro on the Accessibility of Urban Public Transportation Network and the Value-added Response of Land Price $[\mathrm{J}]$. Acta Geographica Sinica, 2014, 02: 255-267. (in Chinese)

[6] Huang Xiaoyan, Zhang Shuang, Cao Xiaoyu. Temporal and Spatial Evolution of Metro Accessibility in Guangzhou and Its Impact on Transit Accessibility [J]. Progress in Geography, 2014, 08: 10781089. (in Chinese)

[7] Ma Rongguo. Research on the Development of Urban Public Transportation System [D]. Chang'an University, 2003. (in Chinese)

[8] Wang Ying. Research on the Theory and Method of Public Transportation Planning Based on Accessibility [D]. Chang'an University, 2015. (in Chinese)
[9] Liu Huasheng. Research on Key Methods for Coordination and Optimization of Urban Rail Transit and Conventional Public Transportation [D]. Jilin University, 2015. (in Chinese)

[10] Zuo Zhongyi. Optimization and Design Method of Bus Passenger Flow Deconstruction in Urban Rail Transit Hub Area [D]. Beijing Jiaotong University, 2013. (in Chinese)

[11] Wei Hua. Research on Key Issues of Rail Transit and Conventional Bus Connection Optimization [D]. Chang'an University, 2014. (in Chinese)

[12] Yu Qiang. "Twelfth Five-Year Plan" Tianjin Opened and Extended the Extension of Bus Line 707. Bohai Morning Post [J/OL]. http://tj.sina.com.cn/news/m/2016-02-17/ Detailifxpmypf3157159.shtml (in Chinese)

[13] Tianjin Rail Transit Group. Tianjin Urban Rail Transit Phase II $\begin{array}{lll}\text { Construction Planning (2015 2020) [EB/OL] } & \end{array}$ http://www.tjgdjt.com/touzi/content_1716.htm, 2014-10-27. (in Chinese) 